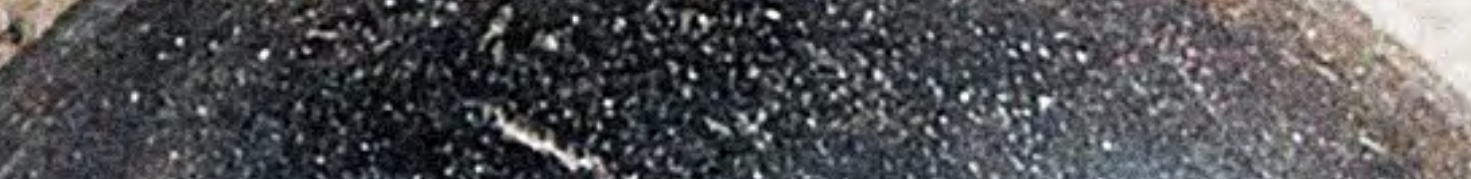

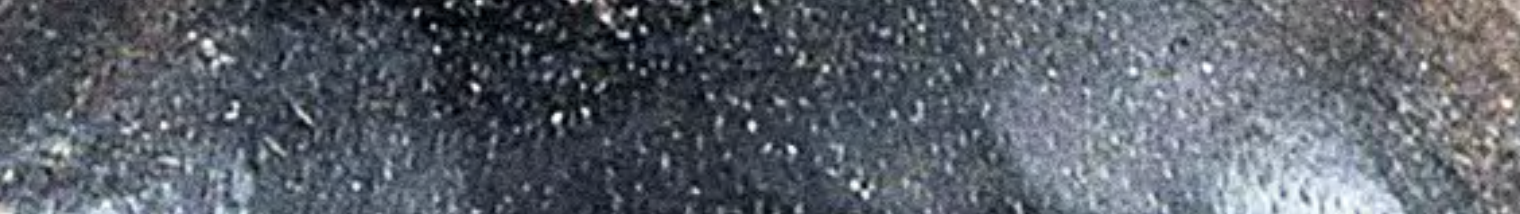

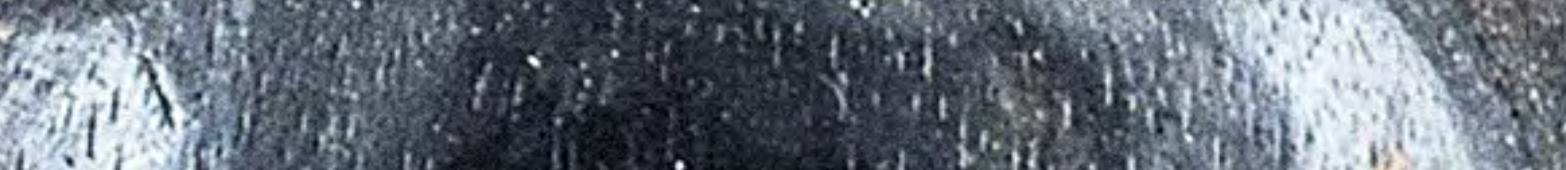

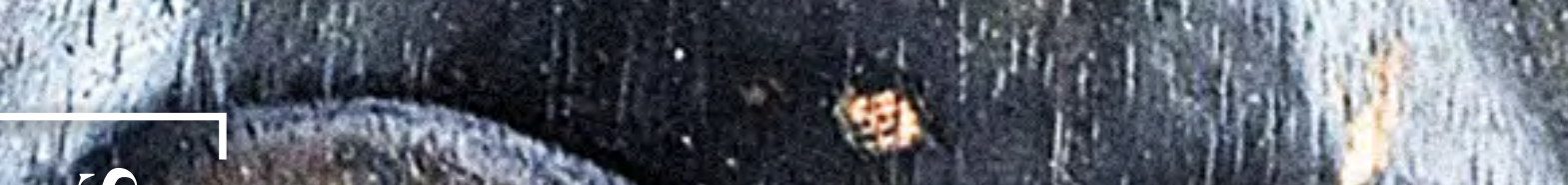

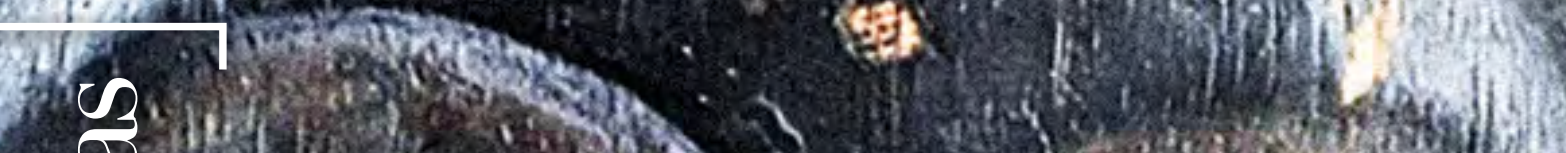
(2)

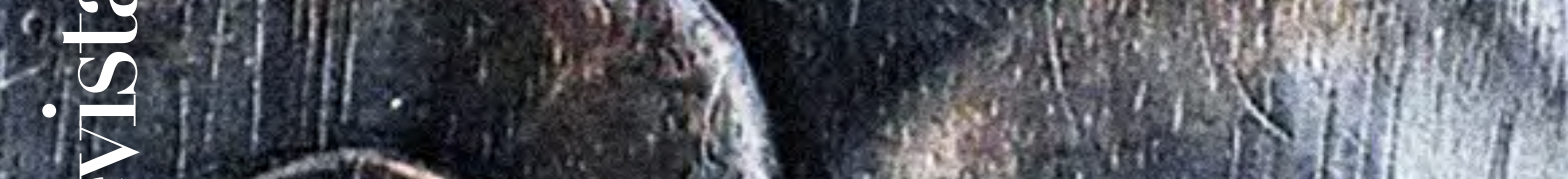

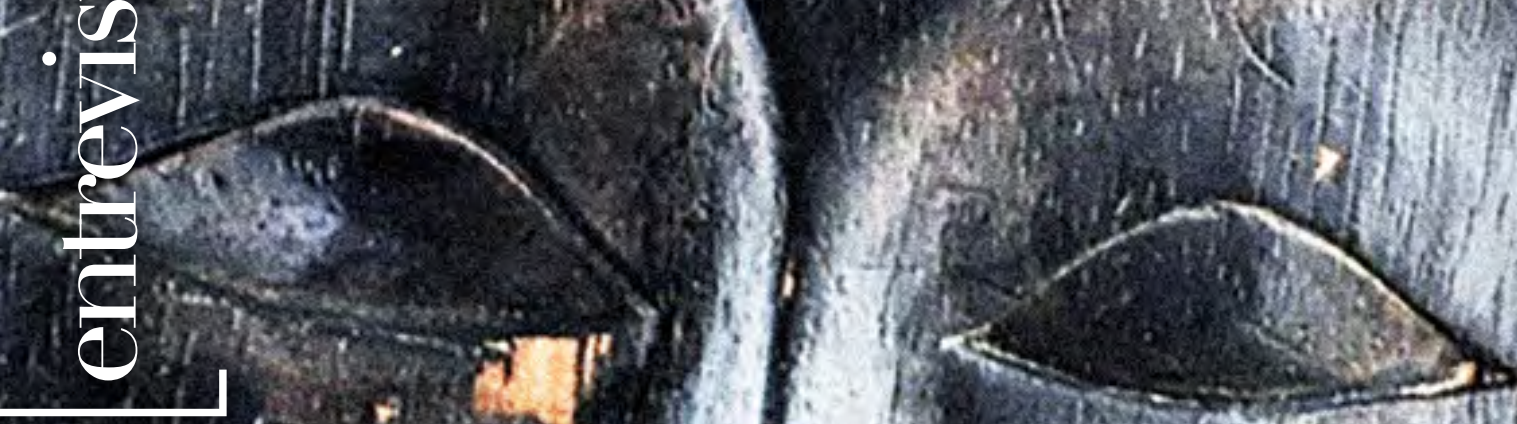




\section{Moda masculina italiana e representacões das masculinidades na perspectiva de
Fabio Quaranta}

[IVANA GUILHERME SIMILI]

Doutora em História; professora do Programa de Pós-Graduação em História da Universidade Estadual de Maringá (UEM-PR).

E-mail: ivanaguisimili@gmail.com

\section{[PAOLO FRANZO]}

Doutorando em Ciências do Design/Fashion Design na Universidade IUAV de Veneza.

E-mail: paolofranzo@iuav.it

\section{[ALESSANDRA VACCARI]}

Professora de História e Teoria da Moda e coordenadora do currículo de Moda do Programa de Pós-Graduação em Artes Visuais e Moda da Universidade IUAV de Veneza.

E-mail: avaccari@iuav.it 
Roupas para homens, moda masculina, vestir masculino e masculinidades/virilidades são assuntos que chamam a atenção e levantam questões. Algumas relativas às diferenciações entre indumentárias, corpo, sexo e gênero; outras, aos papéis dos movimentos sociais, políticos, culturais e do design de moda contemporâneo para romper com as balizas estéticas e estilísticas na criação de roupas para homens.

Transformamos essas questões em motivo para entrevistar o fashion designer italiano de moda masculina Fabio Quaranta. Nascido e criado em Roma, graduou-se em Administração de Empresas. Depois de algumas experiências como consultor de moda para várias empresas, em 2006 criou a FQR, formada pelas iniciais de Fabio Quaranta Roma. 0 lançamento de sua primeira coleção de prêt-à-porter masculina ocorreu no espaço San Martin, em Paris. Nela, a escolha de um caminho como designer de moda masculina: criar roupas que não perdessem de vista a italianidade e a sua cultura de alfaiataria, apresentando-as com uma linguagem contemporânea.

Não por acaso, para levar adiante o que inscrevia na coleção como projeto de moda masculina à italiana, o designer fundou em 2006, no centro de Roma, o Motelsalieri, espaço dedicado à pesquisa e exploração de experiências em moda, arte e música. Em 2010, criou a grife FABIO QUARANTA e, no mesmo ano, venceu o concurso Who is on next? Uomo (Quem é o próximo? Homem), promovido pela AltaRoma, L'Uomo Vogue e Pitti Immagine. Na coleção, os projetos de difusão da moda feita na Itália e do Motelsalieri se fundem. 0 uso de tecidos finos do lanifício Bottoli, fundado em 1861, e a inspiração na música, na banda inglesa Current 93, caracterizam a estética das peças. As camisas e calças dos ternos são reinterpretadas por meio de tecidos e texturas; camisetas estetizadas com inspiração musical, como propostas para o vestir masculino na virada do século XXl, impactam e causam boa impressão na mídia de moda.

Em meio ao reconhecimento por seu trabalho como fashion designer, em 2010, iniciou sua trajetória como professor de Design de Moda masculina na Universidade IUAV de Veneza, no Programa de Pós-Graduação em Artes Visuais e Moda. As relações entre a prática e a pesquisa permanecem em ambas as atividades, bem como no projeto Motelsalieri que, em 2017, foi transferido de Roma para Milão.

Aproveitamos esta entrevista para conhecer o percurso profissional de um dos nomes mais conhecidos na Itália quando o assunto é a moda masculina italiana. No encontro com Quaranta, tratamos de abordar problemáticas relativas às interpretações das roupas para o vestir dos homens, como um dos protagonistas contemporanêos dessa história na Itália. Desse modo, com a ajuda de Quaranta, procuramos entender os cruzamentos entre moda feminina e masculina que não cessaram de inquietar e intrigar desde o fim do século XIV até o início do XV, quando a separação entre linhas indumentárias para homens e para mulheres significou os corpos com cortes e destaques para algumas partes, transformando-as em simbólicas da virilidade/masculinidade e da feminilidade. Ombros, peito e pernas para os homens; decotes, seios e quadris para as mulheres instituiam maneiras de perceber e identificar os corpos e os papéis dos gêneros 
nas relações e práticas sociais (LIPOVESTKY,1987; CRANE, 2000). No século XIX, na interpretação de Flügel (1930), teria ocorrido o que se denomina de "grande renúncia" dos homens à moda masculina. Acompanhando as transformações econômicas, sociais, culturais e políticas, oriundas da austeridade e da moralidade burguesa, as roupas designadas aos homens adquiriram novos significados, imprimindo novas relações dos homens com a moda masculina. 0 terno, composto por calças e paletó reforçaram os simbolismos para os papéis dos ombros e das pernas nas narrativas das masculinidades e de seus controles corporais. 0 terno foi transformado em uniforme simbólico da virilidade, controlada pelos códigos da vida pública do trabalho, dos negócios. Com essas interpretações, a produção historiográfica recente (BREWARD, 1999; COLE, 2014) tem mostrado que 0 interesse dos homens pelo consumo de moda sempre existiu. Mas qual é o papel da moda masculina no século XXI e como se articula com o atual debate sobre indumentária unissex e a "crise da masculinidade" (PAYNE, 1995, p.12)? E na Itália, o que aconteceu (e o que vem acontecendo) com a moda masculina, em seus elos com a tradição da alfaiataria e as imagens de homens amantes latinos, sedutores e bem vestidos (MALOSSI, 1996; 2000)? No trabalho de Fabio Quaranta, essa tradição se mistura aos ecos de masculinidade popular e proletária imersa na Itália do segundo pós-guerra graças à contribuição visual do cinema neorrealista de Giuseppe De Santis, Vittorio De Sica, Roberto Rossellini e Luchino Visconti. E também às imagens dos "dândis subproletários" e de garotos de rua de "corporalidade púbere" (COLAIACOMO, 2015, p. 273) que permearam a obra literária e filmica de Pier Paolo Pasolini.

Considerando a ampla rede de leituras e interpretações para a moda masculina, especificamente a italiana, é que levamos algumas dessas problemáticas para Fabio Quaranta. 0 que ele tem a dizer sobre os laços entre o passado e o presente na moda italiana masculina? De que maneira instrumentaliza as roupas para questionar concepções de gênero que atrelam corpos e performances de masculino e feminino? 0 que tem a dizer sobre a moda unissex? Quais seriam os papéis dos vestuários nas lutas sociais, culturais e políticas contra os preconceitos provocados pelo binarismo entre masculino e feminino? Vamos conhecer seus pensamentos...

Quais são as suas referências na criação de moda? Quem e quais fatores exercem influências na sua produção?

Sou estimulado continuamente por tudo que está à minha volta e interfere no meu modo de criar. A pesquisa é de fluxo contínuo, e não apenas iconográfica, de materiais e formas, mas inclui diversos âmbitos, ela é o ponto de partida. A coleta e as manipulações dos materiais são as bases das criações. As definições e as análises dos detalhes conduzem à revisão do projeto inicial, que se reitera até o momento em que há coerência com a ideia inicial.

Como nasceu a experiência Antonio Salieri e Motelsalieri? Por que esses nomes?

0 projeto Antonio Salieri está na origem do Motelsalieri. Ele surgiu como um coletivo de pessoas próximas a mim que tinham ideias e objetivos semeIhantes para produzir experiências e pesquisas em arte, música e moda. Pessoas que tinham habilidades e competências diferentes e que se dispuseram a 
desenvolver um trabalho coletivo. Para nomear o projeto, queriamos um nome masculino e, entre as opções existentes, escolhemos o de um compositor italiano contemporâneo de Mozart, Antonio Salieri. 0 fio da experiência iniciada em 2006 permanece na história do Motelsalieri: o constante confronto de ideias, de posições, sem perder de vista o diálogo, o debate, a colaboração entre as pessoas. Quanto ao nome Motelsalieri, é a transposição da ideia de casa temporária, como um motel, no qual artistas e designers são convidados a desenvolver e a apresentar seus projetos.

Como você situa a sua trajetória na tradição da alfataria masculina de Roma e da Itália?

A pesquisa contemporânea sobre a tradição da alfaiaria e, sobretudo, a sua atualização são o DNA do meu trabalho. As minhas experiências com a alfaiataria Litrico de Roma, em 2010, no trabalho de reinterpretação do terno de J.F. Kennedy, e depois, em 2013, com Andrea Caraceni, da alfaiataria Tommy e Giulio Caraceni, na criação de um casaco inspirado no filme de Zurlini, $L a$ prima notte di quiete, são evidências de que, nesse pais, e em Roma, particularmente, por causa desses detalhes, detemos um conhecimento único que está em via de extinção porque os empresários do setor não investem na sua preservação.

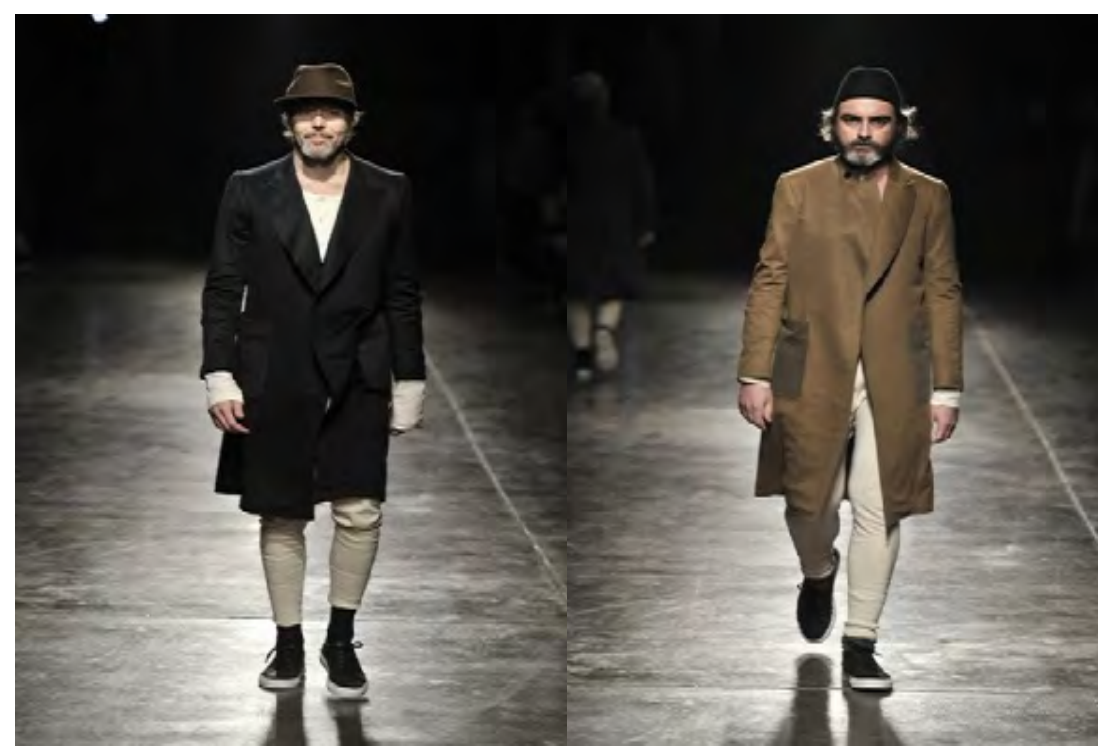

Figura 1: FABIO QUARANTA, Outono/Inverno 2013.

Fonte: $<h t t p: / / w w w . f a b i o q u a r a n t a . i t />$. Fotógrafo: Graziano Ferrari.

Quais são os desafios de uma marca independente como a Fabio Quaranta?

Sobreviver ao sistema e aos grandes grupos, permanecendo coerente com a própria ideia de moda, sem apegar-se às exigências do mercado, e continuar a explorar mundos novos.

Qual é a sua concepção de moda masculina e o que significa ser um designer de roupas para homens?

Do meu ponto de vista, um designer de moda masculina é um empresário que cria roupas que, por convenção, fazem parte do guarda-roupa masculino: indumentárias para homens e não somente para eles, isto é, criadas para 
homens, mas não destinadas exclusivamente aos homens. Então, não é uma questão de gênero, no sentido de que as minhas roupas podem ser usadas não somente por eles.

Como a marca Fabio Quaranta se posiciona a respeito do tema da moda sem gênero?

A esse respeito, procuro desenvolver roupas que permitam pensar nas possibilidades das indumentárias, para criar estéticas que questionem, que rompam com os binarismos de masculino e feminino. Enfim, as minhas roupas possibilitam várias apropriações e, por essa razão, penso que a marca Fabio Quaranta faz várias contribuições, as quais revelam os papéis que os desginers de moda podem desempenhar nas sociedades e culturas a fim de produzir novos conceitos e comportamentos nas relações das pessoas com as aparências, com as noções de estéticas individuais/coletivas.

Como esse pressuposto de moda sem gênero, ou do papel da moda na crítica social da existência de um sistema binário, se faz notar na sua criação de indumentária? Por exemplo, como a sua maneira de pensar esteve presente nos imaginários das coleções de 2016 e 2017 ?

Uma peça de roupa não tem gênero, mas é definida somente por uma classificação convencional, a qual é social e cultural. É a pessoa que, ao usá-la, Ihe atribui uma identidade.

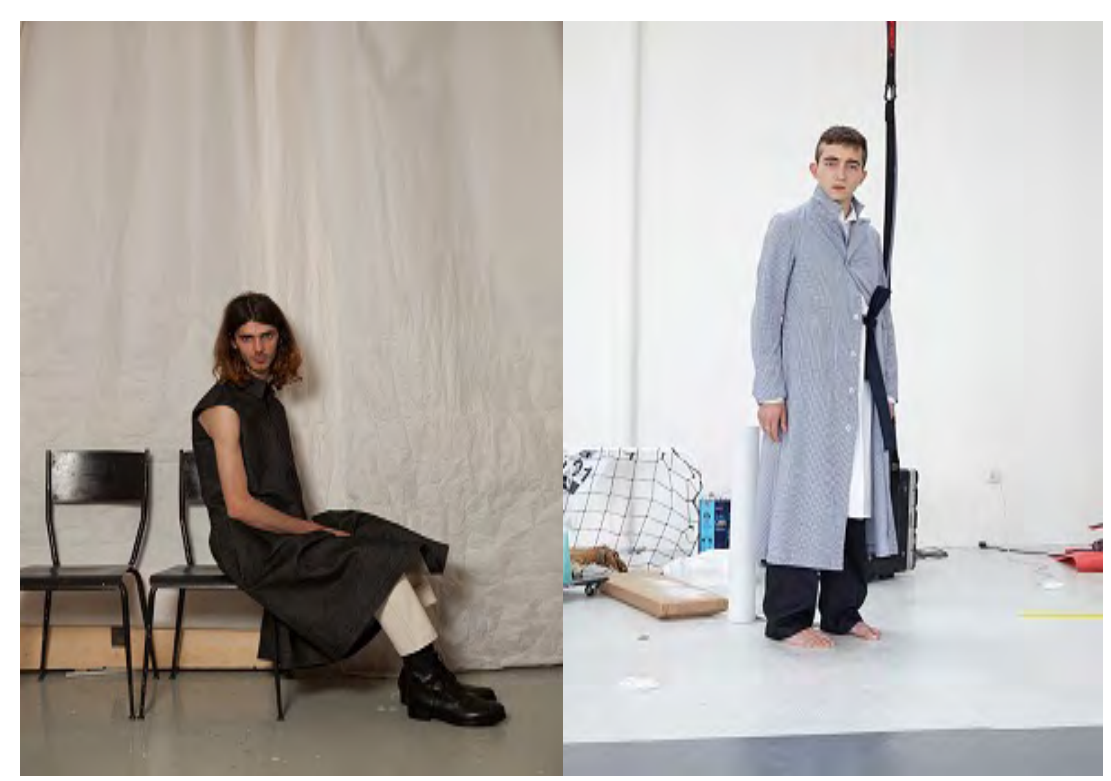

Figura 2: FABIO QUARANTA, Primavera/Nerão 2016 (esquerda) e Primavera/Verão 2017 (direita). Fonte: <http://www.fabioquaranta.it/>. Fotógrafos: Peppe Tortora (esquerda) e Dario Salamone (direita).

Como essa complementaridade se faz notar nas suas coleções?

Creio que as duas fotografias representam bem a ideia de complementaridade que desenvolvo nas minhas coleções. Uma roupa com o mesmo design veste homem e mulher. 


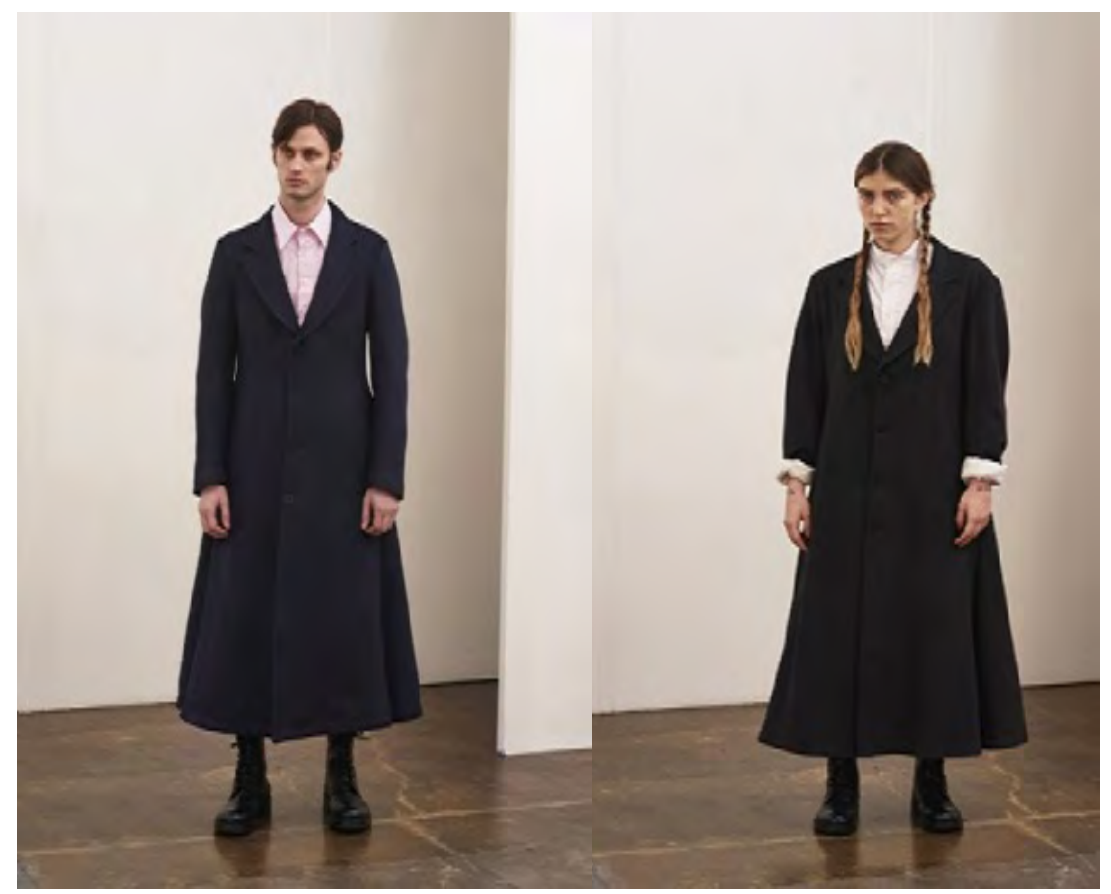

Figura 3: FABIO QUARANTA, Outono/Inverno 2015.

Fonte: <http://www.fabioquaranta.it/>. Fotógrafa: Ph: Marta Colli.

Anne Hollander, em O sexo e as roupas (1994), escreveu que não é possivel entender a moda feminina sem considerar a masculina e vice-versa. Enquanto designer, como interpreta essa afirmação?

Acredito que é absolutamente verdadeira. Ainda que os tipos de roupas sejam potencialmente intercambiáveis e as identidades confusas, os dois modos são, para mim, complementares.

$\mathrm{Na}$ história do estilismo italiano, quais foram os designers que transformaram as roupas em veículos para construir um novo conceito de moda masculina? Você pode dar exemplos do passado e do presente?

Creio que, primeiro, Nino Cerruti e, depois, Giorgio Armani são nomes do estilismo italiano que devem ser lembrados. Ambos desempenharam um papel importante ao desenvolver roupas com formas novas e mais confortáveis, antecipando o sportswear, e que até hoje continuam profundamente atuais. Dolce \& Gabbana é o líder de uma geração inspirada no folk italiano. Romeo Gigli e Miuccia Prada, na minha opinião, marcaram o início de uma nova era de minimalismo. Maurizio Altieri' é porta-voz do pós-modernismo internacional do século XXI.

Como conciliar a tradição dos alfaiates italianos com a exigência de renovação da imagem masculina?

Os costureiros têm os pressupostos e os esquemas que permanecem inalterados por décadas. Quero, por um lado, destruir e subverter essas certezas, por outro, remanipular as técnicas dos alfaiates de modo a contribuir com a sua preservação. 
"Um homem para ser considerado masculino não precisa se preocupar com sua aparência, porque a masculinidade não é considerada uma função da aparência", escreveu Diana Crane (2000, p. 354). 0 que pensa dessa afirmação?

Estou convencido de que a masculinidade tem a ver com o modo de se relacionar com o mundo, e não com a aparência. A estética, no caso, transforma-se em consequência da ética, em outras palavras, no modo como os homens conduzem a vida. Nesse sentido, a aparência desempenha papel secundário.

Como a experiência em pesquisa e como docente universitário influencia a sua trajetória como designer?

Essa experiência tem sido muito importante porque me coloca a necessidade de teorizar sobre o que eu havia vivenciado/experimentado na prática, dando-me novos argumentos para trabalhar.

Quais são as principais referências teóricas usadas por você como professor de moda masculina?

Esses são alguns autores que menciono no laboratório de Design de Moda Masculina e que, no meu modo de entender, são importantes referências para os estudantes: Christopher Breward (The hidden consumer: masculinities, fashion and city life, 1860-1914), Cally Blackman (Questione di stile: 100 anni di abbigliamento maschile), Hywel Davies (Modern menswear), James 209 ] Sherwood (The London cut: Savile Row, l'arte inglese della sartoria), David Kuchta (The three-piece suit and modern masculinity: England, 1550-1850), Michael P. Londrigan (Menswear: business to style).

Como você trabalha com os seus alunos de Design de Moda a ideia de moda masculina e feminina? Ainda é válida a diferença ou, nos estudos, as fronteiras parecem menos definidas?

Houve uma época em que era muito dificil, para aqueles que chegavam à universidade sem ter feito um percurso especifico ou mesmo havendo feito, conseguir executar com êxito a criação de roupas para os dois gêneros. Hoje, na época do unissex, a tendência de criar roupas sem distinção, para o homem ou para a mulher, comete um erro fundamental. A moda é a arquitetura do corpo e o instrumento da identidade. Você pode projetar a roupa para um corpo que não existe, mas precisa ter clareza sobre o fato de que não pode omitir a questão da identidade. Como designer e professor, procuro transmitir a necessidade da coerência do projeto, da qualidade da criação e da organização do trabalho, incluindo a troca de comunicação com os técnicos. Na prática, mostro os diferentes pontos de vista contidos em uma ideia, e que antes de tudo é preciso ter clareza do que se quer fazer.

Como a beleza masculina é representada na sua marca e quais evoluções são observadas?

Sóbria e intima. Tento imprimir essas caracteristicas nas minhas roupas usando vários recursos, que vão da escolha dos tecidos ao público que pretendo ver usando as minhas criações. A beleza, nesse contexto, deve parecer algo 
anônimo, mas na realidade não é. Ela é uma construção realizada pela pessoa e, como tal, foi pensada desde o projeto de um designer até o consumidor que, ao usar uma roupa, realiza uma escolha orientada pelo que considera belo ou pelas potencialidades de um vestuário produzir sensações de estar bem vestido e belo.

Você é a imagem de sua marca?

Não, são os meus clientes. Aqueles que ainda compram pelo prazer de usar, e não de mostrar.

${ }^{1}$ Maurizio Altieri é designer de moda independente e criador da marca artesanal Carpe Diem.

\section{REFERÊNCIAS}

BREWARD, Christopher. The hidden consumer: masculinities, fashion and city life, 1860-1914.

Manchester: Manchester University Press, 1999.

COLAIACOMO, Paola. L'eleganza faziosa. Pasolini e l'abito maschile. Venezia: Marsilio, 2007.

. Pier Paolo Pasolini and the construction of masculinity in italian fashion. In: International Journal of Fashion Studies, vol. 2, n. 2, 2015, pp. 267-285.

COLE, Shaun. Sexuality, identity and the clothed male body. PhD thesis, University of the Arts London, 2014.

CRANE, Diane. Fashion and its social agendas: class, gender, and identity in clothing. Chicago: University of Chicago Press, 2000.

FABIO QUARANTA. Disponivel em: <http://www.fabioquaranta.it/>

FLÜGEL, John Carl. Psychology of clothes. London: Hogarth Press, 1930.

HOLLANDER, Anne. Sex and suits. New York: Knopf, 1994.

LIPOVESTKY, Gilles. L'empire de l'éphémère: la mode et son destin dans les sociétés modernes. Paris: Gallimard, 1987.

MALOSSI, Giannino (ed). Latin lover: the passionate south. Milano: Charta. 1996.

_. Material man: masculinity, sexuality, style. New York: Harry N. Abrams, 2000.

MOTELSALIERI. Disponivel em: www.motelsalieri.com..

PAYNE, Leanne. Crisis in masculinity. Grand Rapids, Mich: Baker Books, 1995. 